specialist registration and the EEC. I wish to make it understood that the Overseas Doctors' Association is seeking the right of freedom of movement in the European Economic Community for all overseas doctors who are British nationals and fully registered to practise in this country and not specialists only.

S A A GILAN Overseas Doctors' Association in the UK Manchester

\section{Distinction awards}

SIR,-Dr C I Haines (18 March, p 721) has missed the point which was made by Drs D B Shaw and G H Hall (4 March, p 582). Some system must exist to ensure that worthwhile extracurricular work is rewarded. Research and development certainly should be, by analogy, if the rewards of private practice attract men of intelligence and energy. It is irrelevant to bring the question of full or part-time commitment into this issue. My colleagues Drs Hall and Shaw are both, incidentally, part-timers.

Royal Devon and Exeter Hospital

W B WRIGHT (Heavitree),

SIR,-We knew we should risk leg-pulling, but our study of the composition of the advisory committees (18 February, p 456) has provoked letters from two ex-chairmen, Lord Platt (4 March, p 582) and $\mathrm{Mr} \mathrm{B} \mathrm{H}$ Price (11 March, p 652), whose tone (one "standing up to be counted") suggests that we touched a raw nerve. Mr Price and the West Midlands do deserve credit for the local effort he describes to be fair, but we doubt if, even with prior homework, "almost an entire day" is enough to evaluate the order of merit in which to rank several hundred consultants from 20 different specialties, especially when the committees are slanted in their own composition. We have shown that the top seven specialties best at getting awards are, in fact, over-represented on the advisory committees ( 2879 consultants with 187 seats), three- or fourfold compared with the bottom seven (4544 consultants with 88 seats). It seems that Lord Platt and $\mathrm{Mr}$ Price see nothing at all wrong with this ("the most democratic form of award-selection I have ever known"-Mr Price) and, for all we know, they may be right to focus more on our conspicuous personality defects. The impartial reader must decide.

We are glad at Lord Platt's frank admission that secrecy was meant to minimise quarrelling -a good reason but outweighed by far too many others. The ex-chairman's goodhumoured digs about underlings and chips and shoulders do nothing to efface our sense of older colleagues who have done precisely what Lord Platt and Mr Price suggestnamely, working out their professional lives, developing their subject with devotion, and attaining considerable reputations here and abroad-yet they approach retirement with nothing.

In pressing his case for the special treatment of those specialties he sincerely admires most Lord Platt asks for butter on both sides of the bread. If intense competition for careers in some fields does produce such an oversupply of distinguished consultants it cannot also be these same specialties which need the extra cash to keep enough good recruits in this country. It is a shabby argument either way neither we nor Lord Platt stayed here for the money.

Finally, we were wryly entertained by Lord Platt's suggestion that we take a lead from Cassius ("The fault, dear Brutus, lies not in our stars but in ourselves ..."), the instigator of a conspiracy to put a knife in a friend's back. The "fault" in Brutus was to have scruples. Et tu, Platt?

S BOURNE

Tavistock Clinic,

P BRUGGEN

London NW3

\section{General practitioners' contract}

SIR,-With all the discussion at present going on over a new general practitioners' contract may I please air my own views?

There is nothing whatever wrong with our present contract except that it does not reward us sufficiently for our rapidly increasing work load. The basic idea of a per caput payment is a good one and I personally cannot see anything else being practical or workable considering all the facets of our work. What is needed is a realistic payment for out-of-hours duties, and this must include every weekend from 12 noon on Saturday and must run from $7 \mathrm{pm}$ at night and not $11 \mathrm{pm}$. This must be a reasonable professional fee for a professional responsibility. Then and only then will the Government, and in turn the patient, realise our worth.

I personally work an eight-hour day from $8.30 \mathrm{am}$ to $6.30 \mathrm{pm}$. I, of course, have a twohour lunch break and if I did not I would want to take up alternative employment. What really upsets me is being hauled out of my bed or having to work after my day's work is over for no payment or a payment that is derisory.

Let us opt out of all out-of-hours commitment until we are paid what we are worth. The Government can then agree or provide an alternative service-for example, a deputising service. I know that we will all live longer and enjoy our work more.

Let us not "throw the baby out with the bathwater" in our negotiations on a new contract. Let us keep what is a good system and one that has worked for all these years. What we must have is a realistic payment for our night and weekend work or, as is our perfect right, opt out of it completely.

Bristol

D C HoGG

\section{"The Way Forward"}

SIR,-It is difficult to accept that $\mathrm{Mr} \mathrm{J} \mathrm{A}$ Girling (25 March, p 790) seriously disagrees with DHSS policy regarding allocation of resources.

No one can argue that the pressures arising from continuous increase in population of the elderly loom very large in the problem of achieving a balanced allocation of resources. It is estimated that the number of over-75s, who are the heaviest users of health and personal social services, will rise by half a million over 10 years from 2.3 to 2.8 million. The data quoted by $\mathrm{Mr}$ Girling serve to emphasise this point further. It must be conceded that the policy as outlined in The Way Forward has been based on a very careful examination of Health Service requirements, considered as a national strategic problem, and therefore the result of thorough and well-informed deliberations, the emphasis mainly being on increased rationalisation in the use of available resources and more effective use of available staff. ${ }^{1}$

It is true that continued development of acute services is essential, but it is not suggested in The Way Forward that these services should be drastically cut; the suggestion, rather, is that in view of the growing demand on the available resources for the care of the elderly allocation of resources must inevitably suffer to some extent owing to the need for overall rationalisation because of the financial constraints.

Few areas have enough geriatric beds in general hospitals with immediate access to diagnostic, therapeutic, and rehabilitation facilities; the presence of acute geriatric beds in a general hospital enhances liaison between geriatric medicine and other specialties, which in itself contributes to better use of available resources. ${ }^{2}$ This is likely to achieve improved care of the elderly in general, as very often they have multiple diseases, including possible acute surgical conditions. Improved care of the elderly not only increases turnover, reduces waiting lists, and prevents irreversible deterioration of the patient's condition, but also prevents the blocking of other beds, including acute surgical.

The above measures should not only serve to nullify the effects of any marginal cuts in provisions for acute services as outlined in the DHSS documents but would also benefit the elderly considerably.

N K ChaKRavorty

St Luke's Hospital,

Huddersfield

1 Department of Health and Social Security, Priorities in the Health and Social Services: The Way Forward. London, HMSO, 1977.

${ }^{2}$ Department of Health and Social Security, Priorities for Health and Personal Social Services in England.

\section{Wasted women doctors: a fallacy}

SIR,-Dr Peter Richards states (14 January, p 95): "To marry the career aspirations of women doctors with their domestic responsibilities has proved both too difficult and too expensive for Britain" (my italics). "Misuse of language pollutes thought," and his statement must be corrected lest it harm not only the future contribution of women in medicine, but, in so doing, the medical profession as a whole.

(1) "Marry," as a metaphor of marriage brokerage between two concepts, is confusing here where the marriage of women to men is obviously relevant. (2) "Career aspirations" are what women who choose to be mothers naturally eschew while remaining dedicated to the practice of medicine. (3) The accepted term is "medical women," as in Medical Women's Federation. (4) "Domestic responsibilities" are borne by both men and womenmany a medical man has given up career aspirations, without giving up medical practice, because of his domestic responsibilities. Isn't it the "maternal responsibilities" of some medical women which are irritating our postgraduate sub-dean? His assertion now 